Ergebnisse:

\begin{tabular}{|c|c|c|c|}
\hline & $\begin{array}{c}\mathrm{I} \\
100 \mathrm{Sr} \Theta_{3} \\
+21 \mathrm{Ea} \theta_{3} \\
\end{array}$ & $\begin{array}{c}\mathrm{II} \\
100 \mathrm{Sr} \theta_{3} \\
+15 \mathrm{Ca} \theta_{3} \\
\end{array}$ & $\begin{array}{c}\text { II } \\
100 \mathrm{Sr} \mathrm{C \theta}_{3} \\
+13 \mathrm{Ga} \mathrm{C \theta}_{3} \\
\end{array}$ \\
\hline angewandt & $\begin{array}{l}1,3460, g \mathrm{Sr} \in \theta_{3} \\
0,2876 \text { g } \mathrm{Ca}_{3}\end{array}$ & $\begin{array}{l}1,2378 \mathrm{~g} \cong \mathrm{CO}_{3} \\
0,1846 \mathrm{~g} \mathrm{Ca} \theta_{3}\end{array}$ & $\begin{array}{l}1,8744 \mathrm{~g} \mathrm{Sr} \mathrm{C \theta}_{3} \\
0,2406 \mathrm{~g} \mathrm{Ca} \mathrm{CO}_{3}\end{array}$ \\
\hline erhalten & $\begin{array}{c}1,6656 \mathrm{~g} \mathrm{Sr} S \theta_{4} \\
0,1614 \mathrm{~g} \mathrm{Ga} \theta\end{array}$ & $\begin{array}{c}1,5332 \mathrm{~g} \text { Sr } 5 \theta_{4} \\
0,1046 \mathrm{~g} \operatorname{~} \mathrm{\theta} \theta\end{array}$ & $\begin{array}{c}2,3232 \mathrm{~g} \text { sr } \mathrm{S} \vartheta_{4} \\
0,1334 \mathrm{~g} \mathrm{Ga} \Theta\end{array}$ \\
\hline entsprechend & $\begin{array}{l}1,3379 \mathrm{~g} \text { sr } € \theta_{3} \\
0,2882 \mathrm{~g} \in \mathrm{Ca} \theta_{3}\end{array}$ & $\begin{array}{l}1,2316 \mathrm{~g} \text { Sr } \in \theta_{3} \\
0,1848 \mathrm{~g} \in \mathrm{Ca} \theta_{3}\end{array}$ & $\begin{array}{l}1,8632 g \mathrm{Sr} \in \theta_{3} \\
0,2404 g \mathrm{Ga} \in \Theta_{3}\end{array}$ \\
\hline $\begin{array}{l}\text { auf } 100 \text { Theile } \\
\text { der angewandten } \\
\text { Substanzen ge- } \\
\text { funden }\end{array}$ & $\begin{array}{r}99,4 \mathrm{Sr} \in \theta_{3} \\
100,2 \in \mathrm{Ga} \in \theta_{3}\end{array}$ & $\begin{array}{l}99,5 \mathrm{Sr} \in \theta_{3} \\
100,1 \in \mathrm{Ea} \in \theta_{3}\end{array}$ & $\begin{array}{l}99,4 \mathrm{Sr} \in \theta_{3} \\
99,9 \in a \in \theta_{3}\end{array}$ \\
\hline
\end{tabular}

Die etwas zu niedrig ausgefallenen Ergebnisse der Strontianbestimmungen lassen, sich dadurch erklären, dass das Strontiumsulfat doch bekanntlich in verdünnter Salzsäure etwas löslich ist.. Jedoch sind die hierdurch entstehenden Verluste, welche natürlich auch bei sorgfältigster Arbeit nicht zu vermeiden sind, sehr klein und können für die Technik unberücksichtigt bleiben.

Zur quantitativen Analyse der Muttermileh, nebst einem Anhange über Knhmilch.

\author{
Yon \\ Dr. Emil Pfeiffer, \\ Prakt. Arzte in Wiesbaden.
}

1. Bestimmung des Caseines der Muttermileh.

Die Methoden zur Bestimmung des Caseines in der Muttermilch waren bis jetzt vollständig unzulängliche, da wegen der bisher angenommenen Unfällibarkeit des Caseïnes der Muttermilch durch verdünnte Säuren gewöhnlich solche Methoden gewählt wurden, welche alle Eiweisskörper der Milch zusammen niederschlagen (Alkohol) oder ausserdem sogar noch Producte ergaben, in welchen das Fällungsmittel (Tannin) in einem melır oder weniger beträchtlichen Gewichtsantheile enthalten war. 
Nachdem es mir gelungen war, zu zeigen, dass das Caseïn der Mattermilch durch verdünnte Salzsäure und Essigsäure sicher coagulirt werden kann (Berliner Klinische Wochensehrift. 1882. No. 44 Pag. 666) liess sich die Bestimmung des Caseïnes getrennt von den anderen Eiweissstoffen mit voller Sicherheit ausführen.

Um die Bedingungen, unter welchen die Muttermilcb mit Salzsäure resp. Essigsäure gerinnt, zu studiren, verfährt man folgendermaassen.

Von ganz frischer Muttermilch misst man $2 c c$ mittelst Pipette in ein Reagensröhrchen ab und versetzt sie zunächst mit 3 Tropfen einer sehr verdünnten Salzsäure, welche man aus einer Bürette abtropfen lässt, $(2,2 \mathrm{~g}$ officinelle concentrirte Salzsäare auf $100 \mathrm{~g}$ Aq. destill.; spec. Gewicht 1,0020) mischt gut und bringt das Röhrchen in Wasser von $50-55^{\circ}$ R.; zeigen sich nach einigen Minuten keine Coagulationserscheinungen, so wird eine neve Probe abgemessen und mit 4 Tropien Salzsäure versetzt u. s. f. Zuweilen tritt erst bei 6 resp. 7 Tropfen die Coagulation ein. Es ist besser jedesmal eine neue Probe von 2 cc abzumessen, als derselben Milchprobe immer neue Tropfen Salzsäure zuzusetzen. Die ersten Gerinnungserscheinungen zeigen sich an den dünnen Milchschichten, welche beim Schütteln mit der Salzsäure an den Wänden des Röhrchens zurückgeblieben sind: dieselben erscheinen fein gekörnt. Weiterhin bilden sich deutliche Gerinnselballen, und wenn die Fällung vollständig gelungen ist, so heben sich die Gerinnsel nach oben, indem sie unten ein etwas trübes Serum zurücklassen. Misst man weitere Proben von $2 c c$ ab and fügt denselben immer mehr Salzsäure $\mathrm{zu}$, so tritt sehr bald keine Coagulation mehr anf. Meist sind vom Beginne der Coagulation an $3-4$ Tropfen der oben angegebenen Salzsäure auf $2 \mathrm{cc}$ Muttermilch genügend, die Coagulation wieder aufzuheben.

Obwohl die Coagulation auch bei etwas niedrigerer Temperatur eintritt, so ist doch Wasser von $50-55^{0} \mathrm{R}$. dem Eintritte der Gerinnung am günstigsten.

Die für Gerinnungsversuche passende Essigsïure ist 1 Theil concentrirte Essigsäure auf 50 Theile destillirtes Wasser. Die Art und Weise, die Gerinnung zu demonstriren, ist genau dieselbe wie bei der Salzsäure, jedoch scheint die Essigsäure für die quantitative Bestimmung des Caseines nicht geeignet, da die Gerinnsel so fein werden, dass nicht so leicht, wie bei der Salzsijure, ein klares Filtrat zu erzielen ist. Auch das Durchleiten eines Kohlensäurestromes während $1 / 4$ Stunde macht die Filtrate nicht klar. 
Der Ausführung der quantitativen Bestimmung des Caseĩnes muss bei jeder Muttermilch die oben angegebene Probe vorausgeschickt werden, um zu sehen bei wie viel Tropfen'Salzsäure die betreffende Milch gerade so gerinnt, dass die Gerinnsel sich nach oben heben und Serum sich abscheidet, da die hierzu nöthige (adaequate) Salzsäuremenge für jede Muttermilch verschieden ist. Die eine Muttermich fängt erst bei 7 Tropfen auf $2 c c$ an zu gerinnen, während eine andere bei 7 Tropfen schon nicht mehr gefällt wird.

Nach Bestimmung der »adaequaten Salzsäuremenge wägt man $10 \mathrm{~g}$ Milch auf einer guten Wage möglichst genau in ein Reagensröhrchen $a b$, versetzt sie mit dem Fünffachen der für $2 c c$ gefundenen adaequaten Salzsäuremenge, mischt gut und setzt das Röbrchen in Wasser von $50-55^{\circ} \mathrm{R}$. Während das Wasser langsam erkaltet, scheiden sich die Gerinnsel $a b$ und heben sich nach oben. Nach 10-15 Minuten wird das Röhrchen aus dem Wasserbade genommen und erkaltet dann an der Luft noch vollständig. Jetzt wird der ganze Inhalt des Röhrchens auf ein hinreichend grosses, doppeltes, gewogenes Filter gegossen. Die ersten Tropfen des Filtrates sind, selbst bei Anwendung doppeIter Filter, häufig unklar, besonders wenn die Milch sehr fett ist. Sie werden, sobald die ersten ganz klaren Tropfen am Trichter erscheinen, in das Reagensröhrchen zurückgebracht, dasselbe tüchtig damit ausgespült (durch Schütteln) und sein Inhalt wieder anf das Filter gegossen. Nachdem Alles klar durchgelaufen ist, wird mit höchstens $20 \mathrm{cc}$ destillirtem Wasser ausgewaschen. Auch die ersten Tropfen des Waschwassers werden gesondert aufgefangen, da sie, besonders bei sehr fetter Milch, manchmal trübe sind. Ist Alles klar durchgelaufen, so wird das Filter getrocknet, in einem Soxhlet-Szombathy'schen Aetherextractionsapparate*) von Fett befreit, abermals getrocknet und gewogen.

Da die Salze, der Milchzucker und die löslichen Eiweissstoffe durch das Waschwasser, das Fett durch den Aether aus dem Niederschlage entfernt wurden, so ist der zurückgebliebene Rest des Niederschlages der durch Salzsäure coagulirte Eiweisskörper der Muttermilch oder das Caseïn.

2. Bestimmung des Albumins.

Die Bestimmung des Albumins geschieht durch Kochen des ron dem Salzsäure-Niederschlage erhaltenen Filtrates, welches man mit dem

*) Vergl. diese Zeitschrift 19, 365. 
Waschwasser vereinigt hat. Es bilden sich beim Kochen entweder deutliche Flocken oder es entsteht doch eine beträchtliche Trübung. Die Bildung von Flocken scheint manchmal durch Zusatz von 1-2 Tropfen der oben angegebenen verdünnten Salzsäure befördert zu werden, in anderen Fällen durch Verdünnen des Filtrates, doch ist darüber nichts Bestimmtes ermittelt worden.

Der durch Kochen entstandene Niederschlag wird ebenfalls auf einem gewogenen, am besten doppelten Filter gesammelt, ausgewaschen, getrocknet and gewogen.

Ist beim Kochen nur eine Trübung entstanden, so muss man das Filtrat noch einmal, oder selbst mehrmals, über das Filter giessen, bis das letzte Filtrat vollkommen klar ist. In manchen Fällen bekommt man jedoch auf keine Weise ein ganz klares Filtrat, ein Missgeschick, welches auch bei der Bestimmung des Albumines der Kuhmilch nach Hoppe-Seyler manchmal passirt. Diese nicht auf das Filter zu fixirende Trübung fällt dann nachher dem $\gg$ Eiweissreste

Wiu. Der auf dem Filter gebliebene Rückstand ist das Albumin.

\section{Der Eiweissrest.}

Wenn man das Filtrat ron dem Albuminniederschlage mit einigen Cubikcentimetern einer 10 procentigen Tanninlösung versetzt, so entsteht, auch wenn das Filtrat wasserklar war, doch jedesmal eine mehr oder weniger beträchtliche Trübung, welche sich nach einigem Stehen in einen flockigen Niederschlag verwandelt. Es sei hier sogleich bemerkt, dass derselbe Niederschlag auch in der Kuhmilch entsteht, wenn man dieselbe behufs der Bestimmung des Caseïnes genau nach HoppeSeyler behandelt, d. h. nach Verdünnung auf das 40 fache Volumen mit sehr verdünnter Essigsäure versetzt, einen Kohlensäurestrom durch die Flüssigkeit leitet und aus dem Filtrate das Albumin durch Kochen fällt. Wenn man jetzt das Filtrat von dem Albuminniederschlage mit einigen Cubikcentimetern 10 procentiger Tanninlösung versetzt, so entsteht dieselbe Trübung, resp. derselbe flockige Niederschlag wie bei der Muttermilch. Es ist dieser Niederschlag demnach weder eine Eigenthümlichkeit der menschlichen Milch, noch beruht er auf einer Mangelhaftigkeit der Methode, da ja auch die für die Kuhmilch allgemein adoptirte und vortreffliche Hoppe-Seyler.'sche Methode ihn ebenso auftreten lässt. 
Der Niederschlag könnte allerdings darauf beruhen, dass sowohl durch die Säuren als anch durch das Kochen nicht alles Casein resp. Albumin niedergeschlagen worden wäre. Ebensowohl ist es aber auch denkbar, dass in dem letzten Filtrate nur noch solche Modificationen der Eiweisskörper enthalten sind, welche weder durch Säturen noch durch Kochen niedergeschlagen werden, also peptonartige Körper. Dass die Kuhmilch wenigstens derartige Substanzen enthält, ist von Danilewsky und Radenhausen*) nachgewiesen. Die Nichtfällbarkeit der betreffenden Substanzen durch Säuren und Kochen, sowie ihre Fällbarkeit durch Tannin, sprechen für die peptonartige Natur des Eiweissrestes. Die Möglichkeit, dass auch noch Spuren von Caseïn resp. Albumin in dem Eiweisssreste enthalten seien, ist nicht abzuweisen.

Für die quantitative Analyse der Milch genügt es zu wissen, dass dieser Eiweissrest jedesmal vorhanden ist und dass er deshalb anch jedesmal besouders bestimmt werden muss. $\mathrm{Da}$ in dem mit Tannin erhaltenen Niederschlage jedenfalls das Tannin in einer Art von chemischer Verbindung mit den betreffenden Eiweissstoffen enthalten ist, so ist es wichtig, bei der Bestimmung des Eiweissrestes eine immer gleich starke Tanninlösung anzuwenden um möglichst-vergleichbare Resultate zu erhalten. Es ist daher nothwendig das letzte Filtrat immer auf ein bestimmtes Volumen zu bringen (etwa $50 \mathrm{cc}$ ) und fo $10 \mathrm{cc}$ des Filtrates je $1 c c$ einer 10 procentigen wässerigen Tanninlösung anzuwenden. Auf diese Weise wird es möglich sein, eine gewisse Uebereinstimmung unter den verschiedenen Analysen zu erzielen. Am wünschenswerthesten wäre es allerdings, wenn dann noch ausserdem bekannt wäre, wie viele Procente des erhaltenen Niederschlages Albuminate, wie viele Tannin wären, doch scheint dieses Verhältniss sehr zu wechseln.

Nachdem man also das Filtrat von dem Albuminniederschlage auf ein bestimmtes Volumen gebracht hat, fügt man die Tanninlösung zu, lässt einige Zeit stehen, filtrirt auf ein gewogenes Filter, wäscht tüchtig mit destillirtem Wasser aus, trocknet and wägt.

Der Rückstand ist der Eiweissrest.

Die Aufführung von Listen über die Resultate der nach meiner Methode ausgeführten Analysen würde kein Interesse haben, da die Mattermilch ein in seiner Zusammensetzung sehr wechselndes Product

*) Untersuchungen über die Eiweissstoffe der Milch. Forschungen auf dem Gebiete der Viehbaltung. Bremen. 1880. 
ist und daher die nackten Zahlen nichts beweisen würden. Dagegen erscheint es angemessen, die Ergebnisse einiger Analysen anzuführen, bei welchen je 2 Parallelbestimmungen (A $u$. B) vergleichsweise mit derselben Milch angestellt wurden, da dieselben zeigen, dass die von mir vorgeschlagene Methode wirklich constante Resultate liefert.

Als Vorbedingung für das Zustandekommen gleicher Resultate bei derartigen Parallelbestimmungen ist es nothwendig, dass zu der gleichen Menge Milch auch immer die gleiche Menge Salzsäure zugefügt wird, sowie, dass die Coagulationstemperatur dieselbe ist. Dass auch die übrigen Manipulationen, wie Auswaschen, Trocknen u. s. w. für vergleichende Bestimmungen dieselben sein müssen, versteht sich von selbst.

Die Analysen folgen der Zeit ihrer Entstehung nach geordnet. Alle Zahlen sind Procentzahien.

\begin{tabular}{|c|c|c|c|c|c|c|c|c|}
\hline Datum & Reaction & $\begin{array}{c}\text { Spec. } \\
\text { Gewicht }\end{array}$ & & Caseïn & Albumin & $\begin{array}{c}\text { Eiweiss- } \\
\text { rest }\end{array}$ & $\begin{array}{l}\text { Summo der } \\
\text { Piweissstofle }\end{array}$ & Butter \\
\hline \multirow{2}{*}{ 28. Sept. } & \multirow{2}{*}{ Alkalisch } & \multirow{2}{*}{1035,0} & A & 0.659 & 0,110 & 0,504 & 1,273 & 2,241 \\
\hline & & & $B$ & 0,615 & 0,120 & 0,545 & 1,280 & 2,256 \\
\hline \multirow{2}{*}{ 29. Sept. } & \multirow{2}{*}{ Stark alkaI. } & \multirow{2}{*}{1035,2} & $A$ & 0,850 & 0,095 & 0,407 & 1,352 & 1,416 \\
\hline & & & $\mathrm{B}$ & 0,830 & 0,117 & 0,387 & 1,334 & 1,435 \\
\hline \multirow{2}{*}{ 30. Sept. } & \multirow{2}{*}{ Stark alkal. } & \multirow{2}{*}{1035,2} & $\mathrm{~A}$ & 0,714 & 0,150 & 0,317 & 1,181 & 1,548 \\
\hline & & & B & 0,774 & 0,129 & 0,289 & 1,192 & 1,554 \\
\hline \multirow{2}{*}{ 1. October } & \multirow{2}{*}{ Schw. alkal. } & \multirow{2}{*}{1036,2} & $A$ & 0,689 & 0,161 & - & - & 1,106 \\
\hline & & & B & 0,689 & 0,091 & 0,460 & - & 1,075 \\
\hline \multirow{2}{*}{ 6. October } & \multirow{2}{*}{ Alkalisch } & \multirow{2}{*}{1084,5} & $\overline{\mathrm{A}}$ & 0,710 & 0,118 & 0,490 & 1,318 & 1,554 \\
\hline & & & $\bar{B}$ & 0,719 & 0,081 & 0,435 & 1,235 & 1,561 \\
\hline
\end{tabular}

Leider war die Milch, welche zu diesen Analysen verwandt wurde, von schlechter Qualität, d. h. sehr eiweiss- und besonders caseïnarm. Sonst hat die Milch gesunder Fraven durchschnittlich 1,2\% Casë̈n und 1,6-1,7\% Gesammteiweiss. Da jedoch aus anderen Gründen gerade mit dieser Wilch Analysen vorgenommen werden mussten und keine Gelegenheit zur Analysirung anderer Milch gegeben war, so können auch nur diese gerade vorhandenen Parallelanalysen angeführt werden. 


\section{Anhang}

betreffend den Eiweissrest in der Kuhmilch.

Wie schon vorher erwähnt, zeigt auch die Kuhmilch, wenn man die Eiweissstoffe derselben nach Hoppe-Seyler bestimmen will, den von mir bei der menschlichen Milch aufgefundenen $\gg$ Eiweissrest $*$.

Es bedarf daher die Hoppe-Seyler'sche Methode der Erweiterung, dass man in jedem Falle diesen Eiweissrest besonders bestimmen muss.

Man bringt zu diesem Zwecke das Filtrat von dem Albuminniederschlage auf ein bestimmtes Volumen und fügt für je 10 cc desselben, je $1 c c$ einer 10 procentigen wässerigen Tanninlösung hinzu.

Hierdurch wird wenigstens eine gewisse Uebereinstimmung in den Analysen erzielt, so lange der Antheil des Tamnins an dem entstehenden Niedersehlage nicht genauer präcisirt werden kann.

Der Eiweissrest in der Kuhmilch ist nicht unbeträchtlich. Er betrug in einer Reihe von Analysen durchschnittlich $0,731 \%$ bei einem Caseingehalte von 2,329\% and einem Albumingehalte ron $0,224 \%$.

\section{Ueber eine neue Methode zur Bestimmung des Stickoxydgases resp. der Salpetersäure. Ton}

\section{Dr. C. Böhmer.}

Von den vielen Methoden, welche man zur Bestimmung der Salpetersäure angegeben hat, sind diejenigen der ausgedehntesten Anwendung fähig, welche auf der Zersetzung der Salpetersäure durch Eisenchlorür beruhen. Sie werden wohl auch allgemein zu den besten gezählt. Die Methoden, nach welchen man den quantitativen Verlauf dieser Reaction verfolgt, sind rerschiedener Art.*) Pelouze bestimmte den Rest des im Ueberschuss zugesetzten Eisenchlorürs, C. D. Braun das durch die Oxydation entstandene Eisenchlorid und endich Schlösing die Quantität des hieraus resultirenden Stickoxydgases. Die Bestimmung des Stickoxyds wiederum kann auf verschiedene Weise geschehen. Schlösing führt es in Salpetersäure über, F. Schulze bestimmt es aus

*) Vergl. Fresenius. Anleitung zur quantitativen chemischen Analyse. 6. Aufl. Bd. I. p. 519. 